\title{
Recepção, tradução, influência e sucesso do Corpus Hermeticum
}

\section{Reception, translation, influence and success of the Corpus Hermeticum}

\author{
David Pessoa de Lira \\ Universidade Federal de Pernambuco, Recife, Pernambuco / Brasil \\ lyrides@hotmail.com
}

Resumo: O presente artigo trata da recepção do Corpus Hermeticum na Renascença, levando em consideração os aspectos da aceitação de evidências literárias da cultura greco-romana antiga nesse período. Assim, analisa-se as relações entre transmissão, interpretação, tradução, influência e sucesso dos textos herméticos do mundo antigo. Este texto objetiva observar a Literatura Hermética na cultura da Renascença para demonstrar como antigas fontes foram submetidas a novas interpretações através da chave hermenêutica da prisca philosophia, prisca sapientia e prisca theologia. Ademais, busca-se evidenciar, por meio de uma análise dos estudos clássicos e dos conceitos de literatura comparada, o modo como o antigo hermetismo modelou as visões e os valores modernos.

Palavras-chave: corpus hermeticum; recepção; tradução; influência; sucesso; prisca theologia.

Abstract: This article deals with the reception of the Corpus Hermeticum, in the Renaissance, taking into account the aspects of the admission of literary evidences of the ancient Graeco-Roman culture in this period. So, one analyzes the relations among transmission, interpretation, translation, influence and success of the hermetic texts of the ancient world. This article aims to observe the Hermetic Literature that in the Renaissance 
culture in order to demonstrate how ancient sources were subjected to new interpretations through the hermeneutic key of the prisca philosophia, prisca sapientia e prisca theologia. Moreover, one seeks to to show up, through an analysis of the classical studies and the Comparative Literature concepts, the way the Ancient Hermeticism shaped the visions and the modern values.

Keywords: corpus hermeticum; reception; translation; influence; success; prisca theologia.

Recebido em: 14 de fevereiro de 2017.

Aprovado em: 10 de julho de 2017.

\section{Introdução}

O Corpus Hermeticum (Corp. Herm., daqui por diante) é uma coletânea composta de dezessete libelli escritos em grego. Por causa de seu conteúdo marcado por uma filosofia religiosa, essa coleção de tratados se associa aos esquemas filosófico-religiosos que caracterizam essa literatura, da qual fazem parte Asclepius Latinus, Stobaei Hermetica, Tratados 6, 7, 8 do codex VI Nag Hammadi, Fragmenta Hermetica, Definições Herméticas Armênias e Fragmentos do Papiro de Viena (MAHÉ, 2005, p. 3939; FILORAMO, 2002, p. 669; JOHNSON, 2009, p. 84).

Esses libretos filosófico-religiosos se desenvolveram no Egito helenístico durante o período de dominação romana, principalmente entre os séculos I e IV da Era Comum (FILORAMO, 2002, p. 669; MAHÉ, 2005, p. 3944). Também é atestado que, mesmo no séc. III a.E.C, já circulavam alguns escritos herméticos de cunho mágico-astrológico. ${ }^{1}$ Sabe-se que a Literatura Hermética era maior do que aquela que existe atualmente. Só se conhece uma parcela dessa imensa literatura antiga (DODD, 2005, p. 11; MAHÉ, 2005, v. 6, p. 3939).

${ }^{1}$ Cf. ELIADE, 1979, p. 60; FILORAMO, 2002, p. 669; MAHÉ, 2005, p. 3938-3939; GONZÁLEZ BLANCO, 1973, p. 358. 
É possível que os escritores herméticos, na Antiguidade, não reconhecessem nenhuma escritura infalível pelo fato de não haver nada que expressasse uma doutrina baseada em escrituras paradigmáticas, canônicas e infalíveis, a fim de serem seguidas estritamente como está escrito nelas. E, em outras palavras, não há qualquer evidência de infalibilidade escriturística. ${ }^{2}$ Não obstante, no período renascentista, eruditos e pensadores, tais como Marsílio Ficino e Giovanni Pico della Mirandola, acreditavam que os escritos herméticos eram divinamente inspirados (ECO, 2004, p. 156-157).

A redescoberta dos escritos herméticos na Renascença fez com que o Corpus Hermeticum pudesse ser interpretado através do humanismo daquele período. Esse é um ponto fundamental para a compreensão do procedimento de Ficino e de Pico della Mirandola mediante o conceito de uma prisca theologia, na qual eles destacavam Hermes Trismegistos como sujeito divino e paradigmático (EBELING, 2011, p. 60). Ao ter reconhecido Hermes como divinamente inspirado, dentro de uma corrente traditiva de filósofos pagãos, Ficino colocou em crise a soteriologia cristã. Assim, ele aceitou como revelação algo que não faz parte da revelação divina dentro do corpo de preceitos e doutrinas do cristianismo (HEISER, 2011, p. 55).

Mircea Eliade chama a atenção ao fato de que:

Muito embora exaltasse a santidade e a veracidade dos textos herméticos, Ficino não suspeitava - nem podia suspeitar - que não era um bom cristão. Já no século II, o apologista cristão Lactâncio considerara Hermes Trismegistos um sábio divinamente inspirado, e interpretara algumas profecias herméticas vendo o seu cumprimento no nascimento de Jesus Cristo. Marcilio Ficino reafirmou esta harmonia entre o Hermetismo e a magia hermética por um lado e o Cristianismo por outro. (ELIADE, 1989, p. 56).

Ficino se sentia um bom cristão, o que, de fato, coube-lhe demonstrar com seriedade como lidou com o seu sacerdócio (EBELING, 2011, p. 60-61; HEISER, 2011, p. 21). No entanto, ele retomou às crenças

${ }^{2}$ Cf. FILORAMO, 1992, v. 1, p. 378; MAHÉ, 2005, v. 6, p. 3940; LOHSE, 2000, p. 252; DODD, 2005, p. 17; SCOTT, 1993, v. 1, p. 7, 8-9; ANGUS, 1929, p. 341. 
de Lactâncio sobre os escritos herméticos. Ficino não era nenhum apologista nem tinha o objetivo de convencer não cristãos sobre a verdade do cristianismo. Pelo contrário, ele tinha como objetivo convencer os cristãos (do séc. XV) de que a verdade expressa no cristianismo também se exprime por não cristãos. Para Ficino, no que diz respeito aos fundamentos da divina revelação, o paganismo hermético-platônico e o cristianismo estavam em concordância (EBELING, 2011, p. 64-65).

\section{A Literatura Hermética e os aspectos gerais do contexto renas- centista}

Sabe-se que o Renascimento marcou o início dos os tempos modernos, principalmente no plano artístico-literário e intelectual. Isso assinala um período que vai do fim do medievo até o século XVII. ${ }^{3}$ A priori, convém salientar alguns pontos importantes. Pesquisadores diferenciam o termo Renascimento do termo Renascença: um seria intelectual e literário; o outro seria a marca artística dos grandes pintores e escultores. No presente texto, as duas terminologias são intercambiáveis porque a literatura é um produto cultural e artístico. Não obstante, é bem verdade que a Renascença inglesa, por exemplo, não é senão voltada para a literatura, intelectualidade filosófico-religiosa e dramaturgia, a despeito de qualquer atividade de pintura e escultura. Isso advém do fato de que a Inglaterra sofreu a influência protestante no séc. XVI (SAARI, P.; SAARI, A., 2005, v. 2, p. 373).

Outrossim, não se pode considerar o Renascimento como uma nova luz ou um renascer de algo que estava morto (como a Idade Média ocidental). O Renascimento só foi possível por causa da preservação da tradição cultural latina (no Ocidente) e grega (no Oriente). Sem essa preservação, seria impossível pensar no Renascimento. Ademais, na verdade, a mentalidade renascentista é o marco final da própria Idade Média. A ideia do Renascimento é justamente uma retomada explícita da Cultura Antiga Greco-Romana que se faz imortalizada (clássica). Deveras, o humanismo, inicialmente, dava ênfase à literatura clássica

\footnotetext{
${ }^{3}$ Cf. a linha do tempo dos eventos relacionados ao Renascimento em SAARI, P.; SAARI, A., 2005, v. 2, p. xv-xxvi.
} 
latina, mas, posteriormente, teve um alcance maior quando os acadêmicos e eruditos começaram a dominar a língua e a literatura gregas. É fato que essa herança cultural não veio da Idade Média ocidental, mas oriental. Os humanistas estavam sempre atentos para descobrir novos textos antigos e a imprensa ajudou consideravelmente no que concerne a esse objetivo (SAARI, P.; SAARI, A., 2005, v. 2, p. 305-306).

Convém mencionar que uma das contribuições para a divulgação do pensamento renascentista se deu através da imprensa. Johann Gutenberg (1397-1468) aperfeiçoou a impressão dos livros, usando letras móveis e metálicas, que se conhece como tipo. Daí, tipografia. Vale salientar que Gutenberg teve outros auxiliares nesse trabalho, como Johann Fust e Peter Schoeffer. O primeiro livro (incunábulo) impresso foi a Bíblia, em dois volumes (um de 1445 e outro de 1456). Os livros impressos até as primeiras décadas de 1500 foram chamados de incunábulos. Incunabula, no latim, significa "berço" ou "princípio" (In: DICIONÁRIO de latim-português, português-latim, 2010, p. 237). Inicialmente, eram semelhantes aos manuscritos, imitando as letras manuscriturísticas e, assim, eram divulgados. Isso praticamente foi seguido por tipógrafos do séc. XV ao XVI (MILLER; HUBER, 2007, p. 160-161). Também se costuma designar de editio princeps a primeira edição impressa de um determinado texto clássico ou de um texto descoberto em manuscritos (ROSSETTI, 2006, p. 356-357).

O Humanismo foi a alma do Renascimento. O apelo ao Homem Universal é um reflexo do enaltecimento da Cultura Greco-Romana da Antiguidade Clássica. Não é por acaso que Pico della Mirandola (1463-1494), ${ }^{4}$ no Renascimento, inspira-se em uma passagem do livro hermético intitulado Asclepius, a saber: "Que grande maravilha, ó Asclépio, é o homem" (propter haec, o Asclepi, magnum miraculum est homo (Asclepius 6). ${ }^{5}$ Assim, é pressuposto que o Homem é capaz de tudo superar e conhecer; é um observador da natureza, conhece a

\footnotetext{
${ }^{4}$ Pico della Mirandola foi discípulo de Ficino. Sobre Mirandola, cf. HEISER, 2011, p. 24-64; EBELING, 2011, p. 65-70; YATES, 1964, p. 84-116; ABRÃO, 2004, p. 139-140. ${ }^{5}$ HERMĖS TRISMÉGISTE, 2011, t. 2, p. 301. Cf. a intertextualidade entre Asclepius $6 \mathrm{e}$

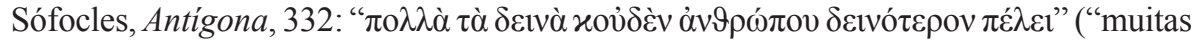
são as maravilhas e nada é mais maravilhoso do que o homem”. Tradução nossa).
} 
criação (o cosmo), conhece a si mesmo, conhece o Criador. Igualmente, a Literatura Hermética já havia influenciado profundamente o pensamento do mestre de Pico della Mirandola, a saber, Marsílio Ficino (1433-1499), principalmente no que diz respeito ao tema do elogio ao homem, no Corp. Herm. $3^{6}$ e em Asclepius 6 (MAHÉ, 1982, t. 2, p. 6). Ao descrever o ser humano como espectador ( $\vartheta \varepsilon \alpha \tau \eta ̀ \varsigma)$ da criação de Deus, a Literatura Hermética apresenta o mundo (cosmo) como um grande espetáculo mágico (Corp. Herm. 4.2). ${ }^{7}$

O tema do elogio ao homem é extremamente atrativo para o pensamento humanista do Renascimento. O homem renascentista é, sobretudo, um admirador polivalente das artes e das ciências, examinando os seres e os fenômenos segundo as fontes e as origens. Destarte, ele exalta a prisca philosophia, a prisca sapientia e a prisca theologia, indo ad fontes et origines. ${ }^{8}$

Em 1438-1439, houve um Concílio em Florença que reuniu católicos romanos e ortodoxos. Cósimo de Médici, estadista e político da cidade italiana de Florença e fundador da dinastia Médici, conhecido como o pater patriae, foi influenciado por um monge ortodoxo que fazia parte da delegação conciliar ortodoxa. Esse monge se chamava Georgios Gemistos Plethon, um intelectual platonista, que aconselhou Cósimo a fundar uma Academia Platônica. Cósimo amadureceu a ideia de criar uma Academia Platônica em Florença, onde se poderia estudar as línguas antigas, como grego antigo, latim antigo etc. Marsílio Ficino (1433-1499), filho do médico Diotefeci, cujos estudos de grego foram patrocinados por Cósimo de Médici em 1456, se tornou o fundador da Academia Neoplatônica. Marsílio estudou grego desde tenra idade com um exilado bizantino chamado Ioannes Argyropoulos (1415-1487), com o intuito de realizar o sonho de Cósimo. ${ }^{9}$ Entre o Concílio de Florença e

\footnotetext{
${ }^{6}$ HERMÈS TRISMÉGISTE, 2011, 2t, p. 49-50.

${ }^{7}$ HERMÈS TRISMÉGISTE, 2011, 2t, p. 49-50. Sobre o tema do homem microcósmico e o mundo em Literatura Comparada, cf. GUILLÉN, 2015, p. 55-56, 262-264 e 381. ${ }^{8}$ Cf. HEISER, 2011, p. 33-64; EBELING, 2011, p. 64-70; YATES, 1964, passim; ABRÃO, 2004, p. 139-140.

${ }^{9}$ Sobre Ioannes Argyropoulos, cf. COPENHAVER, 1999, p. 284 e 287.
} 
os estudos de Ficino houve as sucessivas invasões turcas e a Queda de Constantinopla (em 1453), fazendo com que vários eruditos bizantinos (gregos) procurassem exílio na Itália, trazendo consigo manuscritos de textos clássicos; muitos desses eram desconhecidos para os italianos. Esses eruditos vieram a lecionar grego em várias cidades italianas. ${ }^{10}$

\section{Sucesso e influência da primeira tradução e das edições do texto grego do Corpus Hermeticum na Renascença}

Deve-se considerar a influência como um conceito de ordem qualitativa a qual se dá internamente no leitor-escritor. O sucesso é de ordem quantitativa e diz respeito ao número de edições, de traduções e adaptações e isso diz respeito ao leitor. O conceito de fonte está intimamente relacionado ao de influência, com direções distintas entre emissão e recepção (VAN TIEGHEM, 2011, p. 100-107; NITRINI, 2010, p. 127, 169). A influência da Literatura Hermética, na Renascença inicialmente se deu por meio de tradução, imitação, críticas e estudos sobre o hermetismo. Assim, não há como desassociar sua influência e sucesso.

Cósimo de Médici, havendo colecionado vários manuscritos de obras platônicas, repassou para Ficino, afim de que esse traduzisse e também se dedicasse à filosofia platônica. Ficino não tinha ainda começado a tradução das obras de Platão, ou talvez a tenha abandonado, quando, em 1460, o célebre mecenas lhe pediu para dar prioridade à tradução latina do manuscrito grego de uma coleção dos textos de Hermes Trismegistos, trazida da Macedônia para Florença pelo monge Leonardo Di Pistoia, encarregado de encontrar manuscritos de textos antigos. No ano de 1463, um ano antes de Cósimo de' Médici falecer, Ficino concluiu a tradução daquilo que mais tarde viria a ser chamado Corpus Hermeticum. ${ }^{11}$

\footnotetext{
${ }^{10}$ Cf. VAN DEN KERCHOVE, 2012, p. 2; HEISER, 2011,p. 17-18; EBELING, 2011, p. 6061, 64-65; ELIADE, 2011, v. 3, p. 236-237; FAIVRE, 2005, v. 6, p. 3945-3946; BERNAL, 2003, v. 1, p. 156-157; SCOTT, 1993, v. 1, p. 17, 20, 31-33; YATES, 1964, p. 12-14 e 17. ${ }^{11}$ Cf. VAN DEN KERCHOVE, 2012, p. 2; HEISER, 2011, p. 15-17; EBELING, 2011, p. 59-60; ELIADE, 2011, v. 3, p. 236; FAIVRE, 2005, v. 6, p. 3945; BERNAL, 2003, v. 1, p. 24, 153-154; ELIADE, 1989, p. 55-56; SCOTT, 1993, v. 1, p. 31-33; YATES, 1964, p. 12-13; DODD, 1954, p. xiii; MAHÉ, 1982, t. 2, p. 4.
} 
A tradução em forma manuscrita circulou amplamente e teve um sucesso considerável. A circulação da tradução em forma manuscrita teve 41 cópias, inclusive, superando outras dentre suas obras. Sua tradução, isto é, a primeira tradução editada do Corpus Hermeticum, publicada em 1471, foi intitulada de Mercurii Trismegsti Liber de Potestate et sapientia Dei, ou simplesmente Pimander. ${ }^{12}$ É sabido que os manuscritos do Corpus Hermeticum como um todo não apresentavam nenhum título. Alguns tratados (libelli) dessa coletânea haviam recebido uma espécie de cabeçalho. Por exemplo, o cabeçalho do libellus I é o Poimandres de Hermes Trismegistos. Segundo Marsílio Ficino, aquele cabeçalho era o título de toda a obra, sendo dividida em capítulos (SCOTT, 1993, v. 1, p. 17; MAHÉ, 1982, t. 2, p. 3-4).

O manuscrito encontrado por Di Pistoia e repassado a Ficino para a tradução foi o Laurentianus 71, 33. Sendo assim, a tradução do Corpus Hermeticum por Ficino era constituída apenas dos quatorze primeiros tratados. ${ }^{13} \mathrm{O}$ Pimander de Ficino ganhou popularidade e logo se tornou o modelo para ele proceder à tradução dos diálogos platônicos. A primeira edição impressa se difundiu amplamente pela Europa e foi muitas vezes imitada. Em 1471, o Pimander de Ficino foi reeditado 16 vezes até o final do séc. XVI; até 1641 , foi reeditado 25 vezes, sem contar as transcrições de partes do Pimander e as traduções feitas a partir dessa tradução latina. Essa tradução, até os dias atuais, faz parte dos Opera de Ficino (PURNELL JR., 1977, p. 307). Houve traduções do Corpus Hermeticum

${ }^{12}$ Cf. VAN DEN KERCHOVE, 2012, p. 2; HEISER, 2011, p. 42; EBELING, 2011, p. 60; ELIADE, 2011, v. 3, p. 236; FAIVRE, 2005, v. 6, p. 3945; BERNAL, 2003, v. 1, p. 24 , 156; SCOTT, 1993, v. 1, p. 31; YATES, 1964, p. 12-13, 17; DODD, 1954, p. xiii. Mercurii Trismegsti Liber de Potestate \& Sapientia Dei e graeco in latinum traductus a Masilio Ficino... Tarvisii. M.CCCC.LXXI. O Pimander de Ficino foi publicado recentemente em edição bilingue latim-italiano: FICINUS NOVUS. Pimander: Sive de Potestate et Sapientia Dei. A cura di Maurizio Campanelli. Torino: Nino Aragno Editore, 2011.

${ }^{13}$ Cf. MAHÉ, 1982, t. 2, p. 3-4; VAN DEN KERCHOVE, 2012, p. 2; HEISER, 2011, p. 17-18; EBELING, 2011, p. 60-61, 64-65; ELIADE, 2011, v. 3, p. 236-237; FAIVRE, 2005, v. 6, p. 3945-3946; BERNAL, 2003, v. 1, p. 156-157; SCOTT, 1993, v. 1, p. 17, 20 , 31-33; YATES, 1964, p. 14, 17. Ludovico Lazzarelli descobriu um manuscrito do Corpus Hermeticum que continha os últimos tratados. Ele traduziu esses tratados do grego para o latim, vindo a ser publicado em Lyon depois de sua morte (MAHÉ, 1982, t. 2, p. 4). 
em outras línguas, tais como a italiana e a francesa, tendo como base o Pimander de Ficino. ${ }^{14}$ Ademais, deve-se salientar que a editio princeps do tratado hermético Asclepius, foi publicada com a tradução do Pimander. Textos platônicos também foram publicados com o Corpus Hermeticum nesse período (MAHÉ, 1982, t. 2, p. 4; YATES, 1964, p. 17). Mesmo que a tradução do neutro do plural Hermes Trismegisti Opuscula de Patrizzi tenha vindo a ser publicada em Londres em 1611, sendo traduzida em 1649, parte do Pimander de Ficino, inclusive seu Argumentum para essa obra, foi editada, em 1547, na Inglaterra, tendo sido revisada, ampliada e reeditada várias vezes (GILL, 1984, p. 222-225).

De qualquer forma, Ficino só veio a escrever a theologia Platonica posteriormente e imprimir em 1482. Ele traduziu as obras platônicas entre 1483 a 1484, e as obras plotinianas foram traduzidas em 1492 (SCOTT, 1993, v. 1, p. 31, nota 2). Nesse período, Ficino já tinha sido influenciado pelos escritos herméticos tanto intelectualmente como em estilo. A influência que a personagem mítica Hermes Trismegistos e os escritos herméticos exerceram sobre o pensamento de Marsílio Ficino é importante.

No entanto, uma edição do texto grego do Corpus Hermeticum só surgiu na metade do século XVI. As edições impressas do texto grego do Corpus Hermeticum se originaram a partir da cópia de um único manuscrito. Sendo assim, os editores reproduziram tipograficamente a configuração textual tanto quanto possível, inclusive adicionando notas marginais corretivas que incidiam em um único manuscrito disponível como diferentes leituras. As três primeiras edições do texto grego do Corpus Hermeticum que foram produzidas dessa forma são a editio princeps de Turnebus, a edição bilíngue greco-latina de Flussas e os libelli de Hermes Trismegistos editados por Patrizzi.

O texto grego do Corpus Hermeticum foi impresso e editado pela primeira vez em Paris, no ano de 1554, como resultado do trabalho tipográfico do intelectual católico francês Adrien Turnèbe (Adrianus

${ }^{14}$ Cf. MAHÉ, 1982, t. 2, p. 3-4; VAN DEN KERCHOVE, 2012, p. 2; HEISER, 2011, p. 17-18; EBELING, 2011, p. 60-61, 64-65; ELIADE, 2011, v. 3, p. 236-237; FAIVRE, 2005, v. 6, p. 3945-3946; BERNAL, 2003, v. 1, p. 156-157; SCOTT, 1993, v. 1, p. 17, 20, 31-33; YATES, 1964, p. 14, 17. 
Turnebus), tornando-se, assim, editio princeps do Corpus Hermeticum. ${ }^{15}$ Sua edição recebeu o título Mercurii Trismegisti Poemander, seu de Potestate ac sapientia Divina. Aesculapii Definitiones ad Ammonem regem. ${ }^{16}$ Essa edição segue todos os padrões de um incunábulo.

Essa editio princeps de Turnebus (Turn.) ${ }^{17}$ foi baseada em um único manuscrito, cuja configuração textual se assemelha àquela do manuscrito Vindobonensis Phil. 102. Também, no final dessa edição,

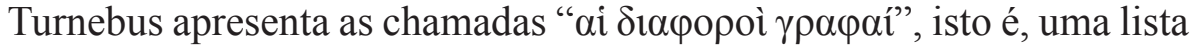
de diferentes configurações de palavras (variantes) para as passagens

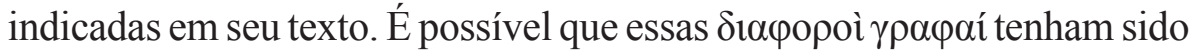
escólios ou glosas marginais do manuscrito utilizado por Turnebus e que tenham se originado das leituras do texto grego do Corpus Hermeticum como se configuram no manuscrito Laurentianus 71, 33 assim como de possíveis conjecturas do próprio compilador. ${ }^{18}$

A edição de Turnebus evidencia as técnicas filológicas empregadas no período renascentista, com notas marginais e referências externas ao texto do Corpus Hermeticum. A editio princeps, diferentemente da tradução de Ficino, contém o texto do C. H. I-XVIII. Entre o Mercurii Trismegisti Poemander e as Aesculapii Definitiones, ou seja, entre o Corp. Herm. 1 a 14 e o Corp. Herm. 16 a 18, Turnebus incluiu dois Stobaei

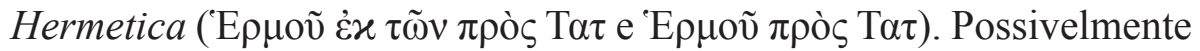
ele imprimiu esses excertos como um apêndice ao Corp. Herm. 1 a $14 .{ }^{19}$

${ }^{15}$ Cf. VAN DEN KERCHOVE, 2012, p. 2; NOCK; FESTUGIÈRE, 2011, t. 1, p. XXV, XXXII-XXXIII; EBELING, 2011, p. 64; FAIVRE, 2005, v. 6, p. 3947; SCOTT, 1993, v. 1, p. 17, 33; YATES, 1964, p. 172-173.

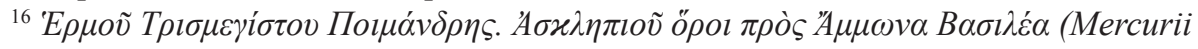
Trismegisti Poemander, seu de Potestate ac Sapientia Divina. Aesculapii Definitiones ad Ammonem regem). Pariis: M.D.LIIII (1554). Apud Adr. Turnebum typographum Regium. Cf. SCOTT, 1993, v. 1, p. 33; YATES, 1964, p. 4401, n. 2.

${ }^{17}$ Turn. é a abreviatura para o texto grego da editio princeps de Turnebus. Cf. NOCK; FESTUGIÈRE, 2011, t. 1, p XXV, XXXII,-XXXIII, LIII; SCOTT, 1993, v. 1, p. 33. ${ }^{18}$ NOCK; FESTUGIÈRE, 2011, t. 1, p. XXXII-XXXIII; SCOTT, 1993, v. 1, p. 17, 33-34; REITZENSTEIN, 1922, p. 321.

${ }^{19}$ VAN DEN KERCHOVE, 2012, p. 2; NOCK; FESTUGIÈRE, 2011, t. 1, p. XXV ss, XXXII-XXXII; SCOTT, 1993, v. 1, p. 22-23, 34; REITZENSTEIN, 1922, p. 321, 327. 
Em 1574, vinte anos depois de ter surgido a editio princeps de Turnebus, o bispo de Aire, François Foix-Candalle (Franciscus Flussas Candalla) publicou uma edição bilingue greco-latina do Corpus Hermeticum na cidade de Bordeaux. A edição de Flussas, sob o título Mercurii Trismegisti Pimandras ${ }^{20}$ foi baseada no texto grego da edição de Turnebus, sem nenhum emprego direto de manuscritos. ${ }^{21} \mathrm{O}$ texto latino paralelo ao grego é o mesmo da tradução de Ficino para o C. H. I-XIV, enquanto que para o C. H. XVI-XVIII, ou seja, o Aesculapii Definitiones ad Ammonem regem, Flussas utilizou a tradução latina de Ludovico Lazzarelli (de 1482, editada em 1507). Contudo, a edição de Turnebus já circulava em paralelo com a tradução de Ficino e de Lazarelli, o que contribuiu para a confecção de uma edição bilíngue greco-latina. ${ }^{22} \mathrm{~A}$ edição bilíngue de Flussas apresenta correções ao texto de Turnebus, sendo devidamente indicadas, tanto no texto como à margem, com uma cruz $(\dagger) .{ }^{23}$ Dessa maneira, pode-se recorrer às leituras de Turnebus que ficam à margem para substituir as emendas de Flussas no texto. Aquelas

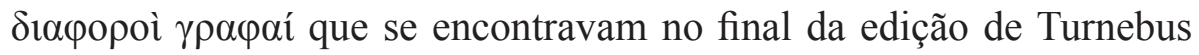
também foram conservadas juntamente com as erratas tipográficas de Flussas ao final da edição (SCOTT, 1993, v. 1, p. 34).

O Mercurii Trismegisti Pimandras de Flussas foi reimpressa em 1600. Mas antes, em 1591, Francesco Patrizzi (Patritius) havia publicado os tratados do Corpus Hermeticum entre vários materiais em sua obra Nova de universis philosophia. ${ }^{24}$ Essa obra de Patrizzi era constituída

${ }^{20}$ Mercurii Trismegisti Pimandras utraque lingua restitutus. D. Francisci Flussatis Candallae industria. Burdigalae, Apud SiomenemMillangium Burdigalensium Typographum via Iacobea, 1574. Cf. SCOTT, 1993, v. 1, p. 22-23.

${ }^{21}$ Cf. EBELING, 2011, p. 64; FAIVRE, 2005, v. 6, p. 3947; BERNAL, 2003, v. 1, p. 156; SCOTT, 1993, v. 1, p. 34; YATES, 1964, p. 173.

22 VAN DEN KERCHOVE, 2012, p. 2; EBELING, 2011, p. 64; FAIVRE, 2005, v. 6, p. 3946-3947; BERNAL, 2003, v. 1, p. 156; SCOTT, 1993, v. 1, p. 34; YATES, 1964 , p. 172-173, 263-264, 401.

${ }^{23}$ Segundo Flussas, em um prefácio para o leitor nessa edição, as emendas foram sugeridas por Josephus Scaliger e outros ("Iosephi Scaligeri [...] non minus doctis linguis eruditi”). Cf. SCOTT, 1993, v. 1, p. 34; YATES, 1964, p. 173.

${ }^{24}$ Cf. EBELING, 2011, p. 64-65; FAIVRE, 2005, v. 6, p. 3948; BERNAL, 2003, v. 1, p. 156; SCOTT, 1993, v. 1, p. 36; YATES, 1964, p. 181-182. 
de vários documentos, ao todo, divididos em cinquenta livros (libris quinquaginta), "entre os quais, por último, foram juntados os oracula 320 de Zoroastro [...], os libelos de Hermes Trismegistos, e os fragmentos [...]" ${ }^{25}$ Se por um lado, para a reprodução do texto grego dos tratados do Corpus Hermeticum, Patrizzi empregou as edições de Turnebus e Flussas; por outro lado, ele fez sua própria tradução latina dos textos. ${ }^{26}$

Embora Patrizzi tenha empregado as edições de Turnebus e Flussas na sua reprodução textual dos tratados, ele procedeu a muitas alterações textuais que podem ter sido baseadas em conjecturas ou em algum manuscrito desconhecido. Algumas de suas conjecturas estão associadas às leituras dos manuscritos Bodleianus 16987 e Bodleianus 3388 (SCOTT, 1993, v. 1, p. 41; REITZENSTEIN, 1922, p. 321-322). Na Holanda, uma tradução neerlandesa foi produzida por Abraham Willemsz, em 1643, e reeditada em 1652, a partir do texto de Patrizzi. Na Inglaterra, a Hermes Trismegisti Opuscula, tradução bilingue grego-latim do Corpus Hermeticum (de Patrizzi,), foi publicada em 1611, sendo traduzida para o inglês por John Everard e editada em 1649 e 1657.27

Não obstante as edições dos textos gregos do Corpus Hermeticum, as traduções seguiram o processo de recepção e influência dos textos herméticos na Renascença.

\section{Prisca Theologia: chave hermenêutica do Corpus Hermeticum}

A redescoberta dos manuscritos e as edições do Corpus Hermeticum se dão justamente no momento de um retorno à prisca philosophia, prisca sapientia e prisca theologia no Período da Renascença. Nessa época, Hermes Trismegistos passou a ser considerado o primeiro dos prisci theologi (teólogos antigos). Com efeito, o Hermetismo e a

\footnotetext{
25 "Quibus postremo sunt adiecta Zoroastris oracula CCCXX [...] Hermetis Trismegisti libelli, et fragmenta [...]". SCOTT, 1993, v. 1, p. 36-37. Grifos e tradução nossos.

${ }^{26}$ Cf. EBELING, 2011, p. 64-65; FAIVRE, 2005, v. 6, p. 3948; SCOTT, 1993, v. 1, p. 36; YATES, 1964, p. 181-182.

${ }^{27}$ Cf. FAIVRE, 2005, v. 6, p. 3949; SCOTT, 1993, v. 1, p. 36; MARTIN, 2014, p. 125.
} 
sua personagem autoritativa vieram a estar em alta conta no mundo filosófico-religioso da intelectualidade renascentista. ${ }^{28}$

Segundo Ficino, em seu Argumentum para o Pimander, Hermes é o autor da teologia, que passa sucessivamente por Orfeu, Aglaofemo, Pitágoras, Filolau até chegar a Platão (Argumentum 30-41) (FICINUS NOVUS, 2011, p. 4). Em outras palavras, Hermes Trismegistos inicia uma cadeia sucessiva de prisci theologi, culminando em Platão, cuja tradição sapiencial se torna elemento comum entre todos eles. Deve-se salientar que, ao percorrer uma cadeia sucessiva de prisci theologi, os renascentistas aventavam um retorno ad fontes (às fontes). Essa busca apaixonante ad fontes pressupunha que a anterioridade (ou a prioridade) era sinônimo de superioridade. Tendo elencado ou categorizado sucessivamente os teólogos antigos desde Hermes Trismegistos, Ficino destacou a proeminência e superioridade de Hermes entre todos os outros por ser fons et origo (fonte e origem) dessa tradição. ${ }^{29}$

Os Escritos Herméticos constituiriam o receptáculo da tradição de Hermes Trismegistos, de onde se poderia retirar os fundamentos herméticos. Como a proeminência de Hermes Trismegistos se torna crescente na Renascença à medida que se fundamenta a importância dele como um homem real (histórico) e divinamente inspirado que viveu em tempos remotos, seus escritos passam a ser reverenciados. Ao reconhecêlo como uma pessoa divinamente inspirada que viveu no Egito em tempos remotos e que redigiu de próprio punho os tratados, simultaneamente se acreditava que seus textos foram escritos em egípcio em tempos antigos. ${ }^{30}$

É bem verdade que o reconhecimento (por cristãos) da autoridade dos Escritos Herméticos e da personagem autoritativa Hermes Trismegistos não é uma mera invenção renascentista. Pelo

${ }^{28}$ Cf. HEISER, 2011, p. 34-63; EBELING, 2011, p. 60-70; ELIADE, 2011, v. 3, p. 236-238; FAIVRE, 2005, v. 6, p. 3946; BERNAL,2003, v. 1, p. 151-169; ELIADE, 1989, p. 55-58; YATES, 1964, p. 14-18, 56- 60, 78, 85, passim; GILL, 1984, p. 222225; PURNELL JR., 1977, p. 305-310.

${ }^{29}$ Cf. FICINUS NOVUS, 2011, p. 3-4; HEISER, 2011, p. 36-37, 41-47; EBELING, 2011, p. 60-64; ELIADE, 2011, v. 3, p. 236-238; BERNAL, 2003, v. 1, p. 153-155, 159; ELIADE, 1989, p. 55-58; YATES, 1964, p. 14-18.

${ }^{30}$ Cf. EBELING, 2011, p. 92-93; ELIADE, 2011, v. 3, p. 236; ECO, 2004, p. 64, 147, 156-157; ELIADE, 1989, p. 56; YATES, 1964, p. 6-9, 12, 14-15, 41-43, 58, 60, 83. 
contrário, várias citações herméticas foram preservadas em textos de autores cristãos do séc. II ao V E.C., tais como Tertuliano (160-220 E.C.), Clemente de Alexandria (séc. II-III E.C.), Lactâncio (240-320 E.C.), Cirilo de Alexandria (375-444 E.C.), e Marcelo de Ancira (no De Sancta Ecclesia - Pseudoantimo - do séc. IV E.C.). Ademais, poder-seia mencionar Agostinho (séc. V). Muitas dessas citações são de obras perdidas, e outras apresentam referências a textos conhecidos, como os tratados do Corpus Hermeticum e o Asclepius Latinus. ${ }^{31}$

Percebe-se que esses autores são de períodos diferentes. Mas, em geral, abrange um período do séc. II ao séc. V E.C. Esse período é marcado pela produção da literatura cristã de caráter apologético. No decorrer do segundo século surgiu um gênero literário cristão conhecido como apologia. Daí vem a designação do segundo século como a Era dos Apologistas. Não obstante, é bem verdade que nos séculos III e IV E.C. os textos cristãos foram mais fortemente influenciados por esse novo gênero (WALKER, 2006, p. 71-74; CARDOSO, 2011, p. 180-183).

Assim sendo, convém destacar três nomes desse período, a saber, Tertuliano, Clemente de Alexandria e Lactâncio. Esses nomes, além do nome de Agostinho, são de suma importância para entender a chave hermenêutica dos renascentistas no que diz respeito ao Corpus Hermeticum.

A citação hermética mais antiga é a de Tertuliano, no De anima, 33.2, datada do séc. II, e se encontra entre os Fragmenta Hermetica: “[...] et Mercurius Aegyptius nouit, dicens animam digressam a corpore non refundi in animam uniuersi, sed manere determinatam, uti rationem [...] patri reddat eorum quae in corpore gesserit" (CORPUS, 2005, p. 1204); (SCOTT, 1993, v. 1, p. 534; VAN DEN BROEK, 2006, p. 492). ${ }^{32}$ Não se sabe ao certo quando os cristãos começaram a produzir textos em latim, já que o grego era, inicialmente, a língua do cristianismo, principalmente, a língua literária. O testemunho mais antigo da literatura cristã escrita em

\footnotetext{
${ }^{31}$ Cf. ELIADE; COULIANO, 2009, p. 172; VAN DEN BROEK, 2006, p. 492; MAHÉ, 2005, p. 3939; COPENHAVER, 2000, p. xxxii; SCOTT, 1993, v. 1, p. 49, 92-95.

32 “[...] também Mercúrio Egípcio confessava, dizendo que a alma retirando-se do corpo não se funde na alma do universo, mas mantém determinada, para que preste conta [...] ao pai das coisas que em corpo tenha feito" (tradução nossa).
} 
latim de que se tem respeito é justamente de Minúcio Félix e Tertuliano; ambos viveram na era dos Apologistas durante a época dos Antoninos (CARDOSO, 2011, p. 180).

Em todo caso, Lactâncio cita o tratado o Corp. Herm. 12 e 16 e talvez faça referência aos tratados 5, 9 e 10 do Corpus Hermeticum. Ademais, ele também conhecia o texto do Asclepius em grego, sob o título de Logos Teleios. Em sua grandiosa obra de sete volumes, Divinae Institutiones (CARDOSO, 2011, p. 183), Lactâncio fez várias referências a escritos herméticos e a Hermes Trismegistos (SCOTT, 1993, v. 1, p. 49, 92-95; VAN DEN BROEK, 2006, p. 493; YATES, 1964, p. 7). Lactâncio e Cirilo são os que mais citam os textos herméticos, tendo uma considerável gama de excertos em seus escritos (VAN DEN BROEK, 2006, p. 493).

A priori, deve-se atentar ao fato de que o reconhecimento de Hermes Trismegistos e dos escritos herméticos pelos Pais da Igreja advém do fato de que eles poderiam empregá-los como um vetor apologético cristão ou de refutação aos não cristãos. Sendo assim, serviriam de suporte para a "verdade cristã" (YATES, 1964, p. 7). Embora os escritos herméticos evidenciassem uma origem pagã, muitos cristãos os interpretavam alegoricamente a partir da sua própria doutrina. Isso facilitava a construção dos argumentos apologéticos dos Pais da Igreja (YATES, 1964, p. 7).

Clemente de Alexandria via na doutrina hermética algo simbolicamente propedêutico que ajudaria a divina verdade cristã a ser transmitida adequadamente às pessoas mais simples. Na verdade, o hermetismo para Clemente é uma espécie de canal equalizador das linguagens religiosas entre a massa pagã e a doutrina cristã. Ao tomar essa posição, Clemente assume que o conjunto de crenças nos escritos herméticos deve ser analisado a partir de uma hermenêutica alegórica adequada, com a finalidade de que o Deus cristão seja discernido como um Deus dos pagãos, passando de um monoteísmo esotérico ao monoteísmo exotérico (EBELING, 2011, p. 39-40). Para ele, era evidente que a teologia hermética, sendo simbólica, deveria ser interpretada simbolicamente a partir de uma chave hermenêutica resultante da dialética entre o exotérico e o esotérico (aparência e significado implícito) (EBELING, 2011, p. 39-40). 
Embora seja importante salientar que Clemente, em sua obra Stromata,$^{33}$ estabelece relações entre a filosofia e a religiosidade pagã com a fé cristã, proporcionando uma abertura para que o hermetismo (a superficialidade do paganismo egípcio) viesse a ser o canal para o cristianismo (o discernimento da verdade cristã), convém chamar a atenção ao fato de que isso é um recurso apologético cristão. Clemente de Alexandria reconheceu a autoridade de Hermes Trismegistos e de seus escritos para que os não cristãos pudessem compreender ou discernir a verdade cristã. Em todo caso, o fato de Clemente reconhecer que existem pontos de contato entre o hermetismo e o cristianismo é de capital importância para que se estabeleça um diálogo entre essas duas grandezas. A descrição e o relato de Clemente confirmam que circulavam escritos, na Antiguidade, sob o nome de Hermes Trismegistos (ou o Hermes Egípcio) e que a literatura hermética da Antiguidade era mais extensa do que a coleção que chegou até os dias atuais (WILLOUGHBY, 2008, p. 155; MAHÉ, 2005, v. 6, p. 3939; DODD, 2005, p. 11).

$\mathrm{O}$ fato de Clemente de Alexandria fazer uma relação dos livros

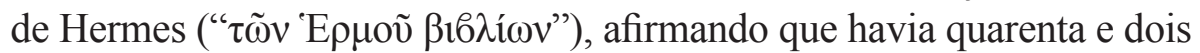
livros de Hermes, dos quais trinta e seis são da sabedoria dos egípcios, estabelecendo sua relação com as funções dos escribas, sacerdotes, cantores e astrólogos, indica seu conhecimento a respeito dos escritos herméticos. Ao tentar mostrar que os egípcios possuíam sua própria filosofia

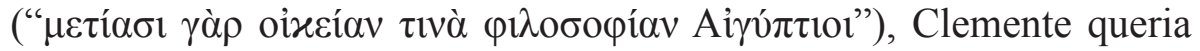
apenas demonstrar que principalmente o cerimonial sagrado dos egípcios

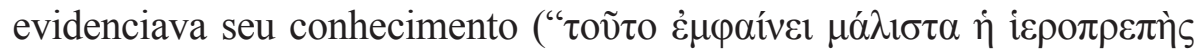

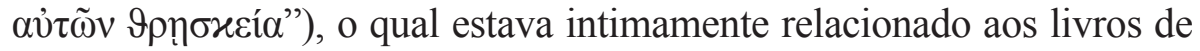

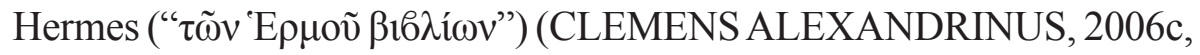
6.4.35 (p. 198-199)). No entanto, não há qualquer plausibilidade em afirmar que o Corpus Hermeticum ou mesmo o tratado Asclepius tenha se originado daquela coleção conhecida por Clemente. Essa crença foi sustentada pelos renascentistas (YATES, 1964, p. 12).

${ }^{33}$ CLEMENS ALEXANDRINUS. Stromata. Mytilene: Lesvos University of Aegean, 2006c. 
De acordo com Durand, um "segundo hermetismo" se origina no séc. III a.E.C. na parte oriental do Mediterrâneo e se desenvolve durante o período imperial romano, nos primeiros séculos da Era Cristã. $\mathrm{O}$ "terceiro hermetismo" é caracterizado pelo ressurgimento do "segundo hermetismo", no séc. XIV, com Marsílio Ficino e Pico della Mirandola, e consequentemente com o neoplatonismo renascentista (DURAND, 2008, p. 166-167).

Lactâncio foi um dos cristãos que testemunhou o desenvolvimento e expansão dos escritos do hermetismo (do "segundo hermetismo"), inclusive citando vários textos que compõem o Corpus Hermeticum e o Asclepius. É através dos testemunhos de Clemente de Alexandria e de Lactâncio (principalmente deste) que os pensadores renascentistas moldaram seus pensamentos acerca de Hermes Trismegistos e dos seus escritos. ${ }^{34}$

[...] homo fuit, antiquissimus tamen et instructissimus omni genere doctrinae adeo, ut ei multarum rerum et artium scientia Trismegisto cognomen inponeret. Hic scripsit libros et quidem multos ad cognitionem diuinarum rerum pertinentes, in quibus maiestatem summi ac singularis dei asserit isdemque nominibus appellat quibus nos dominum et patrem. ac ne quis

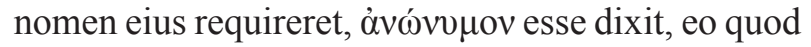
nominis proprietate non egeat, ob ipsam scilicet

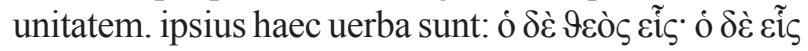

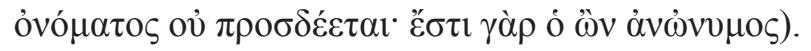
(LACTANTIUS, 1965, 1.6.3-4 (p. 19)). ${ }^{35}$

\footnotetext{
${ }^{34}$ HEISER, 2011, p. 13; EBELING, 2011, p. 39-41, 63; ELIADE, 2011, v. 3, p. 236237; ELIADE, 1989, p. 56; YATES, 1964, p. 6-9, 11, 14-16, 18, passim.

35 “" [...] foi um homem, todavia, muito antigo e muito instruído em todo gênero de doutrina, que, por causa da ciência de muitas coisas e artes, foi the dado o cognome Trismegisto. Ele escreveu muitos livros pertinentes à afinidade das coisas divinas, nos quais semeia a majestade de um deus supremo e singular e o chama pelos mesmos nomes que nós chamamos: senhor e pai. E se alguém perguntasse o nome dele, ele diria que

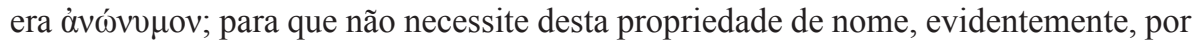
causa da própria unidade. Estas são as palavras do próprio [Hermes]: ó $\delta \dot{\varepsilon} ~ \vartheta \varepsilon o ̀ \varsigma ~ \varepsilon \tilde{c} \zeta{ }^{\circ}$ ó

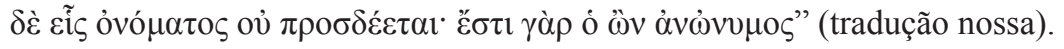


Essas afirmações de Lactâncio evidenciam sua crença de que Hermes Trismegistos; tendo vivido em uma época muito antiga, havia sido instruído em muitas artes do conhecimento, o que fez receber o epíteto de Três-Vezes-Grande, Grandíssimo, Mui Grande. Segundo as afirmações de Lactâncio, Hermes escreveu muitos livros, nos quais ele, em várias passagens, revela a soberania e unicidade de Deus, nomeando-o como Pai e Senhor, assim como o chamam no cristianismo.

Quanto ao fundamento disso, Lactâncio deve ter parafraseado dois textos que marcadamente descrevem Deus como único, senhor e pai, ao qual não se deve aplicar nenhum nome, a saber, Corp. Herm. 5 e Asclepius.

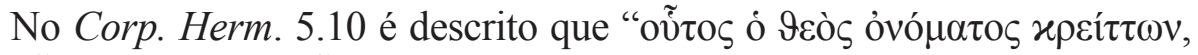

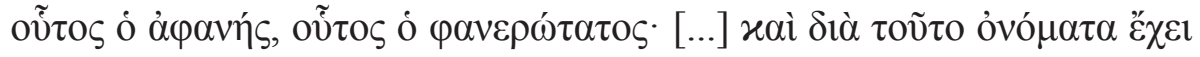

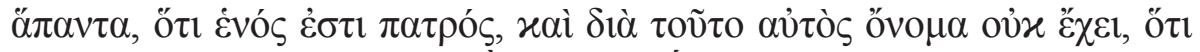

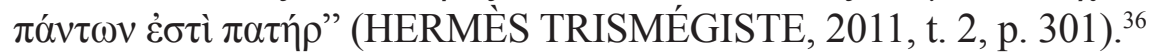
Ainda, em Asclepius, é dito que:

Deus etenim vel pater vel dominus omnium vel quocumque alio nomine ab hominibus sanctius religiosiusque nuncupetur, quod inter nos intellectus nostri causa debet esse sacratum [...] non enim spero: totius maiestatis effectorem omniumque rerum patrem vel dominum uno posse quamuis e multis composito nuncupari nomine, hunc vero innominem vel potius omninominem siquidem is sit unus et omnia, ut sit necesse aut omnia esse eius nomine aut ipsum omnium nominibus nuncupari (HERMÈS TRISMÉGISTE, 2011, Asclepius 20, (p. 320)). ${ }^{37}$

\footnotetext{
36 "Este Deus é maior do que um nome, ele é imanifesto e o mais manifesto: [...] e, por isso, tem todos os nomes, porque são de um único pai; por isso, ele não tem nome, porque é pai de todos" (tradução nossa).

37 "Deus ou o Pai ou o Senhor das coisas, ou por qualquer outro nome que o ser mais santo e venerado seja denominado pelos homens, o que, tendo sido entendido entre nós, por nossa causa, deve ser considerado sagrado [...] não espero que o criador da majestade do Todo, o pai e o senhor de todas as coisas, possa ser denominado por meio de um único nome, nem, tanto quanto se queira, por muitos [nomes]; ele é verdadeiramente inominável ou, antes, todo-nominável, visto que ele é uno e todas as coisas, de maneira
} 
A base de todo argumento de Lactâncio, no que concerne às crenças que incidem nos tratados herméticos, autorizava recorrer às doutrinas de Hermes Trismegistos como profeta pagão que preparou o caminho para o cristianismo.

\section{Conclusão}

Assim, na Divinae Institutiones 6.6.4, Lactâncio retomou o texto de Asclepius 8, em que se descreve a criação do segundo deus, ou seja, o cosmo, dando a interpretação cristã do nascimento do Filho de Deus (Jesus) pelo Pai (Deus). A partir dessa interpretação, Hermes Trismegitos foi acolhido, na Renascença, como um profeta sui generis do paganismo, tendo previsto o surgimento do cristianismo. Outro traço característico dos argumentos de Lactâncio em relação a Hermes Trismegistos foi a descrição de sua antiguidade e sua anterioridade em relação a Pitágoras e Platão. Amiúde, esse autor exaltava a figura de Hermes em detrimento de determinadas práticas religiosas do paganismo, como a magia, o culto das imagens e dos daimones. ${ }^{38}$

É claro que Lactâncio viu nos escritos herméticos algo divinamente inspirado, mas seu objetivo era fazer de Hermes um motivo para apresentar o cristianismo aos não cristãos. Na Renascença, Marsílio Ficino não só reconheceu os argumentos de Lactâncio como certos, mas também se confrontou com uma realidade diferente em relação à redescoberta dos escritos herméticos. Ele estava inserido no mundo cristão de mentalidade medieval. Ao se deparar com um escrito não cristão, ele atentou a um paganismo que ele não conhecia. Ou seja, Ficino encontrou no hermetismo uma devoção que ele não tinha experimentado e que não pertencia a nenhuma religião institucionalizada no Ocidente até então.

\section{Referências}

ABRÃO, B. S. (Org.). História da filosofia. São Paulo: Nova Cultural. 2004.

que é necessário denominar todas as coisas com o nome dele ou que ele seja denominado com os nomes de todas as coisas" (tradução nossa).

${ }^{38}$ Cf. HEISER, 2011, p. 42-43; EBELING, 2011, p. 39-41, 63; ELIADE, 2011, v. 3, p. 236-237; ELIADE, 1989, p. 56; YATES, 1964, p. 6-9. 
ANGUS, S. The Religious Quests of the Graeco-Roman World: A Study in the Historical Background of Early Christianity. New York: Charles Scribner's Son, 1929.

BERNAL, M. Black Athena: The Afroasiatic Roots of Classical Civilization: The Fabrication of Ancient Greece 1785-1985. New Brunswick; New Jersey: Rutgers University Press, 2003 [1987]. v. 1.

CARDOSO, Z. A. A literatura latina. 3. ed. rev. São Paulo: WMF Martins Fontes, 2011.

CLEMENS ALEXANDRINUS. Stromata. Mytilene: Lesvos University of Aegean, 2006c.

COPENHAVER, B. P. Aristotealism. In: POPKIN, R. H. (Ed.). The Columbia History of Western Philosophy. New York: Columbia University Press, 1999. p. 280-292.

DODD, C. H. The Bible and the Greeks. 2. impression. London: Hodder and Stoughton, 1954.

DODD, C. H. The Interpretation of the Fourth Gospel. Reprinted Paperback Edition. Cambridge: Cambridge University Press, 2005.

EBELING, F. The Secret History of Hermes Trismegistus: Hermeticism from Ancient to Modern Times. Forworded by Jan Assmann. Translated from the German by David Lorton. Ithaca; London: Cornell University Press, 2011.

ECO, U. Os limites da interpretação. 2. ed. São Paulo: Perspectiva, 2004.

ELIADE, M. História das crenças e das ideias religiosas: de Maomé à Idade das Reformas. Rio de Janeiro: Zahar, 2011. v. 3.

ELIADE, M. Origens: história e sentido na religião. Lisboa: Edições 70, 1989.

ELIADE, M.; COULIANO, I. P. Dicionário das religiões. 2. ed. São Paulo: Martins Fontes, 2009.

FAIVRE, A. Hermetism. In: JONES, L. (Ed.). Encyclopedia of Religion. 2. ed. Detroit, MI: Thomson/Gale, Macmillan Reference USA, 2005. v. 6. p. 3944-3956.

FICINUS NOVUS. Pimander: Sive de Potestate et Sapientia Dei. A cura di Maurizio Campanelli. Torino: Nino Aragno Editore, 2011. 
FILORAMO, G. Hermetismo. In: DI BERNADINO, A. (Org.). Dicionário patrístico e de antigüidades cristãs. Petrópolis: Vozes, 2002. p. 669-670.

GILL, J. S. How Hermes Trismegistus Was Introduced to Renaissance England: the Influences of Caxton and Ficino's 'Argumentum' on Baldwin and Palfreyman. Journal of the Warburg and Courtauld Institutes, London, v. 47, p. 222-225, 1984. DOI: https://doi.org/10.2307/751453.

GONZÁLEZ BLANCO, A. Misticismo y escatología en el Corpus Hermeticum. Cuaderno de Filología Clásica, Madrid, n. 5, p. 313-360, 1973.

GUILLÉN, C. Entre lo uno y lo diverso: introducción a la Literatura Comparada. Barcelona: Tusquets Editores, 2015.

HEISER, J. D. Prisci Theologi and Hermetic Reformation in the Fifteenth Century. Malone: Repristination Press, 2011.

HERMĖS TRISMÉGISTE. Corpus Hermeticum. Texte établi par A. D. Nock et traduit par A.-J. Festugière. 2. ed. Paris: Les Belles Lettres, 2011.2t.

INCUNABULA. In: DICIONÁRIO de latim-português, português-latim. Porto: Porto, 2010. p. 237

JOHNSON, L. T. Among the Gentiles: Greco-Roman Religion and Christianity. New Haven; London: Yale University Press, 2009.

LACTANTIUS. Divinae institutiones et epitome divinarum institutionum. Recensuit Samuel Brandt. New York; London: Johnson Reprint, 1965.

LOHSE. E. Contexto e ambiente do Novo Testamento. Tradução de Hans Jörg Witter. São Paulo: Paulinas, 2000.

MAHÉ, J.-P. Hermès en haute-Egypte: le fragment du discours parfait et les définitions hermetiques arméniennes. Québec: Presses de l'Université Laval, 1982.t. 2.

MAHÉ, J.-P. Hermes Trismegistos. In: JONES, L. (Ed.). Encyclopedia of Religion. 2. ed. Detroit: Thompson/Gale, 2005. v. 6. p. 3938-3944.

MARTIN, M. Literature and the Encounter With God in Post-Reformation England. Surrey; Burlington (VT): Ashgate, 2014.

MILLER, S. M.; HUBER, R. V. A Bíblia e sua história: o surgimento e o impacto da Bíblia. Barueri: Sociedade Bíblica Brasileira, 2007. 
NITRINI, S. Literatura Comparada. 3. ed. São Paulo, EDUSP, 2010.

NOCK, A.; FESTUGIÈRE, A.-J. Préface et introduction. In: HERMÈS TRISMÉGISTE. Corpus Hermeticum. Texte établi par A.D. Nock et traduit par A.-J. Festugière. 2. ed. Paris: Les Belles Lettres, 2011. t. 1 e 2. p. I-LIII.

PURNELL JR., F. Hermes and the Sibyl: A Note on Ficino's Pimander. Renaissance Quarterly, New York, v. 30, n. 3, p. 305-310, 1977. DOI: https://doi.org/10.2307/2860046.

REITZENSTEIN, R. Poimandres: Studien zur Griechisch-Ägyptischen und frühchristlichen Literatur. Unveränderter anastatischer nachdruck. Leipzig: B.G. Teubner, 1922.

ROSSETTI, L. Introdução à Filosofia Antiga: premissas filológicas e outras "ferramentas de trabalho". São Paulo: Paulus, 2006.

SAARI, P.; SAARI, A. (Eds.). Renaissance and Reformation: Almanac. Detroit, MI: Thomson/Gale, 2005. 2 v. 622 p.

SCOTT, W. Hermetica: the Ancient Greek and Latin Writings Which Contain Religious Or Philosophical Teachings Ascribed to Hermes Trismegistus. Introductions, texts and translation edited and translation by Walter Scott. Boston: Shambala Publications, 1985. v. 1.

VAN DEN BROEK, R. Hermetic Literature I: Antiquity. In: HANEGRAAFF, W. J. (Ed.). Dictionary Of Gnosis And Western Esotericism. Leiden; Boston: Brill, 2006. p. 487-498.

VAN DEN KERCHOVE, A. La voie d'Hermès: pratiques rituelles et traités hermétiques. Leiden; Boston: Brill Academic Pub., 2012.

VAN TIEGHEM, P. Crítica Literária, História Literária, Literatura Comparada. In: CARVALHAL, T. F.; COUTINHO, E. F. (Orgs.). Literatura Comparada: textos fundadores. 2. ed. Rio de Janeiro: Rocco, 2011. p. 100-107. DOI: https://doi.org/10.1163/9789004223653.

WALKER, W. História da Igreja Cristã. 3. ed. São Paulo: ASTE, 2006.

WILlOUGHBY, H. R. Pagan Regeneration: A Study of Mystery Initiations in the Greco-Roman World. South Caroline: Biblio Bazaar, 2008.

YATES, F. A. Giordano Bruno and the Hermetic Tradition. London: Routledge and Kegan Paul, 1964. 